\title{
Clinical, epidemiological, and laboratory features of Rickettsia africae infection, African tick-bite fever: A systematic review
}

\author{
Carlos Ramiro Silva-Ramos' , Álvaro A. Faccini-Martínez ${ }^{2,3}$ \\ ${ }^{1}$ Grupo de Enfermedades Infecciosas, Departamento de Microbiología, Facultad de Ciencias, \\ Pontificia Universidad Javeriana, Bogotá, Colombia; \\ ${ }^{2}$ Department of Pathology, University of Texas Medical Branch, Galveston, TX, USA; \\ ${ }^{3}$ Committee of Tropical Medicine, Zoonoses and Travel Medicine, Asociación Colombiana de Infectología, \\ Bogotá, Colombia
}

Article received 15 June, 2021; accepted 27 July, 2021

\section{SUMMARY}

African tick-bite fever (ATBF), caused by Rickettsia africae, is the main tick-borne rickettsiosis and the second most frequent cause of fever after malaria in travelers returning from sub-Saharan Africa. General descriptions on ATBF were made in the first two decades after recognized as a new infectious entity, and since then, many authors have contributed to the knowledge of the disease by reporting clinical cases in scientific literature. We developed a systematic review that evaluated all available evidence in the literature regarding clinical, epidemiological, and laboratory features of confirmed $R$. africae rickettsiosis cases. We followed the recommendations made by the Preferred Reporting Items for Systematic Reviews and Meta-Analyses guide. A total of 48 scientific publications (108 confirmed cases) were analyzed in order to extract data for developing this review. Overall, our results show that $R$. africae rickettsiosis is more frequent in males in the age group of $18-64$ years, more than $80 \%$ of the cases occurred in European travelers, South Africa was the country where most infections were acquired, and almost $40 \%$ of cases occurred in clusters. Clinically, more than $80 \%$ of the cases had fever and eschar (55\% developed multiple eschars), rash was present in less than the half of cases, and lymphangitis was not a common sign $(11 \%)$. Headache, myalgia and regional lymphadenopathy were predominant nonspecific clinical manifestation (mean of $60 \%, 49 \%$ and $51 \%$, respectively). Our results show that at least $70 \%$ of $R$. africae cases had altered laboratory parameters, most often showing an increase in transaminases and C-reactive protein. Tetracycline-class antibiotics, as monotherapy, were used in most (>90\%) of the patients. Overall, only $4 \%$ of cases had complications, $12 \%$ required hospitalization, and there was a $100 \%$ rate of clinical recovery.

Keywords: Rickettsia, Rickettsia africae, African tick-bite fever, Systematic Review.

\section{INTRODUCTION}

Tnternational travel to Africa, mostly because Lof tourism, has been increasing during recent years, becoming an important risk factor for the emergence and re-emergence of some local infec-

Corresponding author

Álvaro A. Faccini-Martínez

E-mail: afaccini@gmail.com, alfaccin@utmb.edu tious diseases in people from non-African countries [1]. African tick-bite fever (ATBF) is a spotted fever group (SFG) rickettsiosis caused by Rickettsia africae for which the importance has increased as the main tick-borne rickettsiosis and the second most frequent cause of fever after malaria in travelers returning from sub-Saharan Africa [2]. Before the official description of $R$. africae as a new species of the SFG, ATBF was confused with Mediterranean spotted fever, caused by Rickettsia 
conorii, but clinical and epidemiological differences related to complications and geographic areas of these infections had already been noted [3]. In 1992 R. africae was isolated from the blood of a Zimbabwean febrile patient who presented an erythematous lesion behind the right ear in the site of a tick-bite [4]. Polymerase chain reaction (PCR) and restriction endonuclease fragment length polymorphism proved that $R$. africae was distinct from other SFG rickettsiae including $R$. conorii, but identical to isolates from Amblyomma hebraeum and Amblyomma variegatum, ticks species collected in Zimbabwe and Ethiopia, respectively [4-6]. Thus, in 1996 R. africae was officially recognized as the etiologic agent of ATBF [7].

A. variegatum and $A$. hebraeum are considered the main vectors and reservoirs of $R$. africae since infection is maintained through transovarial and transstadial transmission in these ticks [7]. The distributions of $A$. variegatum and $A$. hebraeum are geographically different; the former is distributed through rural areas of central, east and west Africa, and in the eastern Caribbean islands, and the latter is circumscribed to southern Africa [8,9]. These Amblyomma species have an aggressive behavior, and patients are often bitten by multiple infected ticks simultaneously, mainly on the lower extremities [8]. In ATBF endemic areas, native individuals are generally infected at a young age and usually do not seek medical attention because symptoms are not clearly evident (e.g., inoculation eschar is difficult to see in pigmented skin, disease might be mild or subclinical at a young age) [8]. For travelers, popular wildlife activities including hunting, hiking and safari in endemic areas are considered risk factors, as well as travelling during rainy season from November to April, the peak of tick activity [8-10].

Diagnosis of ATBF can be established by isolation and molecular techniques on blood or eschar sample (including eschar swab and skin biopsy), the eschar being more useful for diagnostic confirmation $[10,11]$. Other diagnostic methods include immunofluorescence assay (IFA), western blotting (WB), and cross-adsorption tests, alone or combined, since some patients are not always positive for all the methods [11].

General descriptions of clinical, epidemiological and laboratory features of ATBF were made in the first two decades after the disease was recognized as a new infectious entity, and since then many authors have contributed to the knowledge of the disease by reporting clinical cases in the scientific literature; nevertheless, to our knowledge, no systematic review related to $R$. africae infection (ATBF) has been published. Thus, the aim of this systematic review is to evaluate all available evidence in the literature regarding the clinical, epidemiological, and laboratory features of $R$. africae rickettsiosis.

\section{METHODS}

Search strategy and selection criteria

We followed the recommendations made by the Preferred Reporting Items for Systematic Reviews and Meta-Analyses (PRISMA) to guide all the steps of this review. Searching for scientific literature was carried out on March 18, 2021, in four scientific literature databases: PubMed MEDLINE, EMBASE, Scopus and BVS. Separate searches using the terms ["Rickettsia africae" AND "case"] and ["African tick bite fever" AND "case"] were performed in all the four databases. The references of all the articles were extracted and collected in a library created in "EndNoteX8" program combining both searches. Once the reference list was created, elimination of duplicate articles was carried out using the automatic tool of the program. Results of the procedure provided list of potentially useful articles for analysis and selection.

We reviewed all the literature managed in the eligible list in order to choose those that would be part of this review. Since other pathogenic SFG rickettsiae are endemic to Africa (the main ATBF endemic region), including $R$. conorii, $R$. aeschliman$n i i, R$. sibirica mongolitimonae, and $R$. monacensis, we only included confirmed infections with $R$. africae in order to guarantee the accuracy in our analysis [12]. Thus, the inclusion criteria were case reports, clinical cases, and other papers written in English or Spanish language in which there was a report of confirmed clinical case in humans associated with $R$. africae infection. Those publications that did not fulfill inclusion criteria were excluded.

\section{Data extraction}

We (CRSR, ÁAFM) independently screened the titles and abstracts to identify relevant reports. Possible disagreements were resolved through group discussion. Data were extracted from the included studies and tabulated in an Excel form. For each article, we extracted information related to clinical manifestations of all confirmed cases. Ad- 
ditionally, we also performed the data extraction related to the country of the patient's origin, country of travel where the infection was presumed to have occurred, sex and age of the reported patients, history of cluster infection, history of tick exposure, hematological and biochemical laboratory findings, complications, diagnostic test used including sample type, antibiotic therapy used, need for hospitalization and clinical outcome.

\section{Definitions}

Based on publications of Raoult and Cherry, we defined a confirmed case of $R$. africae infection as a clinically and epidemiologically compatible illness with isolation of $R$. africae in cell culture and/or sequence identification of $R$. africae using PCR-positive products from DNA extracted from clinical samples (blood, serum, eschar, eschar swab, skin biopsy) and/or a Western blot result that showed $R$. africae specific antibodies and/or cross adsorption studies demonstrating homologous antibodies directed against $R$. africae [10, 11].

\section{RESULTS}

Scientific literature search

Figure 1 summarizes our search procedure. Using the terms ["Rickettsia africae" AND "case"], 44, 79,
106 and 93 publications were found in the PubMed MEDLINE, EMBASE, Scopus and BVS databases respectively, giving a total of 322 scientific publications found. The terms ["African tick bite fever" AND "case"] yielded 72, 94, 116 and 117 publications, respectively, in the same databases, giving a total of 399 scientific publications. Combining both search procedures, a total of 721 publications were extracted and loaded in the "EndNoteX8" program in order to eliminate duplicate publications, giving a total of 255 eligible scientific publications.

\section{Literature selection}

From the eligible list of 255 scientific publications, we selected 46 as they fulfilled the inclusion criteria indicated in "Selection criteria". In parallel, we added 2 additional publications that were not found in the databases following our search procedure, which fulfilled the inclusion criteria and reported $R$. africae infection cases confirmed by PCR on blood samples and on eschar biopsy [13, 14]. Thus, a total of 48 scientific publications were analyzed in order to extract data for this review [4, 13-59].

\section{Demographic and epidemiological data}

A total of 108 clinical cases were reported in the 48 analyzed publications [4, 13-59]. Data related

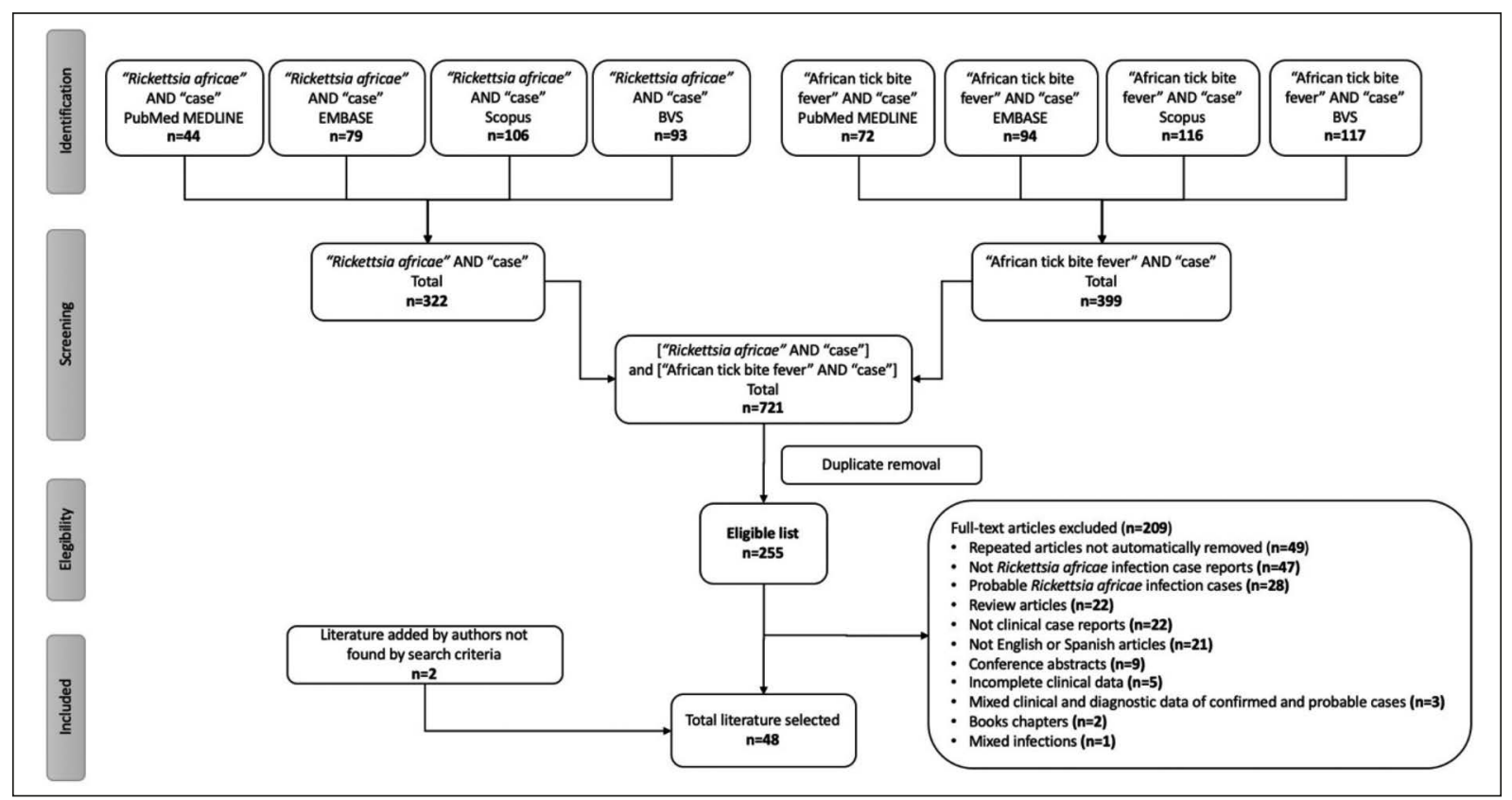

Figure 1 - Search strategy for the systematic review. 
Table 1 - Demographic and epidemiological features of confirmed cases of Rickettsia africae infection

\begin{tabular}{|c|c|}
\hline & $\begin{array}{c}\text { Total cases } \\
n=108\end{array}$ \\
\hline $\begin{array}{l}\text { Age* } \\
\quad 0-17 \\
18-64 \\
\geq 65 \\
\end{array}$ & $\begin{array}{c}2 / 100(2 \%) \\
83 / 100(83 \%) \\
15 / 100(15 \%) \\
\end{array}$ \\
\hline $\begin{array}{l}\operatorname{Sex}^{+} \\
\text {Male } \\
\text { Female }\end{array}$ & $\begin{array}{l}61 / 103(59.2 \%) \\
42 / 103(40.8 \%)\end{array}$ \\
\hline $\begin{array}{l}\text { Autochthonous cases } \\
\text { Cameroon } \\
\text { Zimbabwe }\end{array}$ & $\begin{array}{c}8 / 108(7.4 \%) \\
7 / 8(87.5 \%) \\
1 / 8(12.5 \%)\end{array}$ \\
\hline $\begin{array}{l}\text { Imported cases } \\
\text { Country of origin } \\
\text { France } \\
\text { Italy } \\
\text { Norway } \\
\text { United States } \\
\text { Switzerland } \\
\text { Netherlands } \\
\text { Spain } \\
\text { Germany } \\
\text { Argentina } \\
\text { Poland } \\
\text { Portugal } \\
\text { Sweden } \\
\text { Australia } \\
\text { Austria } \\
\text { Brazil } \\
\text { Israel } \\
\text { Japan } \\
\text { South Korea } \\
\text { Slovenia } \\
\text { Taiwan }\end{array}$ & $\begin{array}{c}100 / 108(92.6 \%) \\
41 / 100(41 \%) \\
11 / 100(11 \%) \\
8 / 100(8 \%) \\
8 / 100(8 \%) \\
5 / 100(5 \%) \\
4 / 100(4 \%) \\
4 / 100(4 \%) \\
3 / 100(3 \%) \\
2 / 100(2 \%) \\
2 / 100(2 \%) \\
2 / 100(2 \%) \\
2 / 100(2 \%) \\
1 / 100(1 \%) \\
1 / 100(1 \%) \\
1 / 100(1 \%) \\
1 / 100(1 \%) \\
1 / 100(1 \%) \\
1 / 100(1 \%) \\
1 / 100(1 \%) \\
1 / 100(1 \%)\end{array}$ \\
\hline $\begin{array}{l}\text { Country of travel } \\
\text { South Africa } \\
\text { Swaziland } \\
\text { Zimbabwe } \\
\text { Tanzania } \\
\text { Ethiopia } \\
\text { Kenya } \\
\text { Uganda } \\
\text { Guadeloupe }\end{array}$ & $\begin{array}{c}74 / 97(76.3 \%) \\
9 / 97(9.3 \%) \\
8 / 97(8.3 \%) \\
2 / 97(2.1 \%) \\
1 / 97(1 \%) \\
1 / 97(1 \%) \\
1 / 97(1 \%) \\
1 / 97(1 \%)\end{array}$ \\
\hline $\begin{array}{l}\text { Cluster infection } \\
\text { Yes } \\
\text { No }\end{array}$ & $\begin{array}{l}43 / 108(39.8 \%) \\
65 / 108(60.2 \%)\end{array}$ \\
\hline $\begin{array}{l}\text { Tick exposure }^{b} \\
\text { Yes } \\
\text { No }\end{array}$ & $\begin{array}{l}43 / 71(60.6 \%) \\
28 / 71(39.4 \%)\end{array}$ \\
\hline
\end{tabular}

$* 8$ cases $[36,39,59]$ were excluded due to missing data.

+5 cases [39] were excluded due to missing data.

a3 patients $[27,28,33]$ were excluded due to traveling to more than one country.

b37 cases [13-15, 22-25, 27, 28, 30-34, 37, 39, 40, 43-45, 47, 51-53, 57, 58] were excluded due to missing data. to age, sex, autochthonous cases, imported cases detailing country of origin and country of travel, history of cluster infection and tick exposure are shown in Table 1. Of all the reported cases, excluding missing information ("no data") of some variables, $2 \%$ were between $0-17$ years, $83 \%$ were between 18-64 years, and 15\% were 65 years of age or older. Regarding sex, 59.2\% were men, and $40.8 \%$ were women. Of all reported cases only $7.4 \%$ were autochthonous and $92.6 \%$ were imported. Origin of autochthonous cases occurred in Cameroon in $87.5 \%$ and Zimbabwe in $12.5 \%$. The origin of imported cases was mostly from France $(41 \%)$, Italy (11\%), Norway $(8 \%)$, United States $(8 \%)$, Switzerland $(5 \%)$, Netherlands and Spain (4\%); a few imported cases have also been reported in other countries such as Germany (3\%), Argentina, Poland, Portugal and Sweden (2\%), and Australia, Austria, Brazil, Israel, Japan, South Korea, Slovenia and Taiwan (1\%) (Figure 2).

Probable country of infection, where travel was reported, mainly corresponded to South Africa (76.3\%), Swaziland (9.3\%) and Zimbabwe (8.3\%); a few cases reported travelling to Tanzania (2.1\%), Ethiopia, Kenya Uganda and Guadeloupe (1\%) (Figure 3). Infection in clusters was reported in $39.8 \%$ of cases, and $60.6 \%$ reported history of tick exposure.

\section{Clinical data}

We analyzed fever, eschar, regional lymphadenopathy, lymphangitis, rash, and other clinical findings (Table 2). From all the reported cases, $89.8 \%$ had fever, $86.1 \%$ presented with an eschar, being a single eschar in $45.2 \%$ and multiple eschars in $54.8 \%$. Enlarged regional lymph nodes were found in $50.9 \%, 11.1 \%$ had lymphangitis, and $41.7 \%$ developed cutaneous rash; $61.4 \%$ were papular, $56.8 \%$ macular, $47.7 \%$ vesicular, and only few cases were pustular $(6.8 \%)$ or purpuric $(4.6 \%)$ $[15,29-48]$.

Other clinical findings included headache $(60.2 \%)$, myalgia (49.1\%), chills $(17.6 \%)$, arthralgia $(9.3 \%)$, fatigue $(9.3 \%)$ and malaise $(6.5 \%)$. Five or fewer patients had cough, sore throat, odynophagia, nausea, back pain, local edema, aphthous stomatitis, diarrhea, abdominal pain, asthenia, hepatomegaly, sweating, neck pain, somnolence, anorexia, or conjunctivitis $[15,22,23,28,29,33,35,45$, $51,53,58]$. 
Figure 2 - Countries with imported and autochthonous cases of Rickettsia africae infection.

Figure 3 - Countries of travel related to imported cases of Rickettsia africae infection.
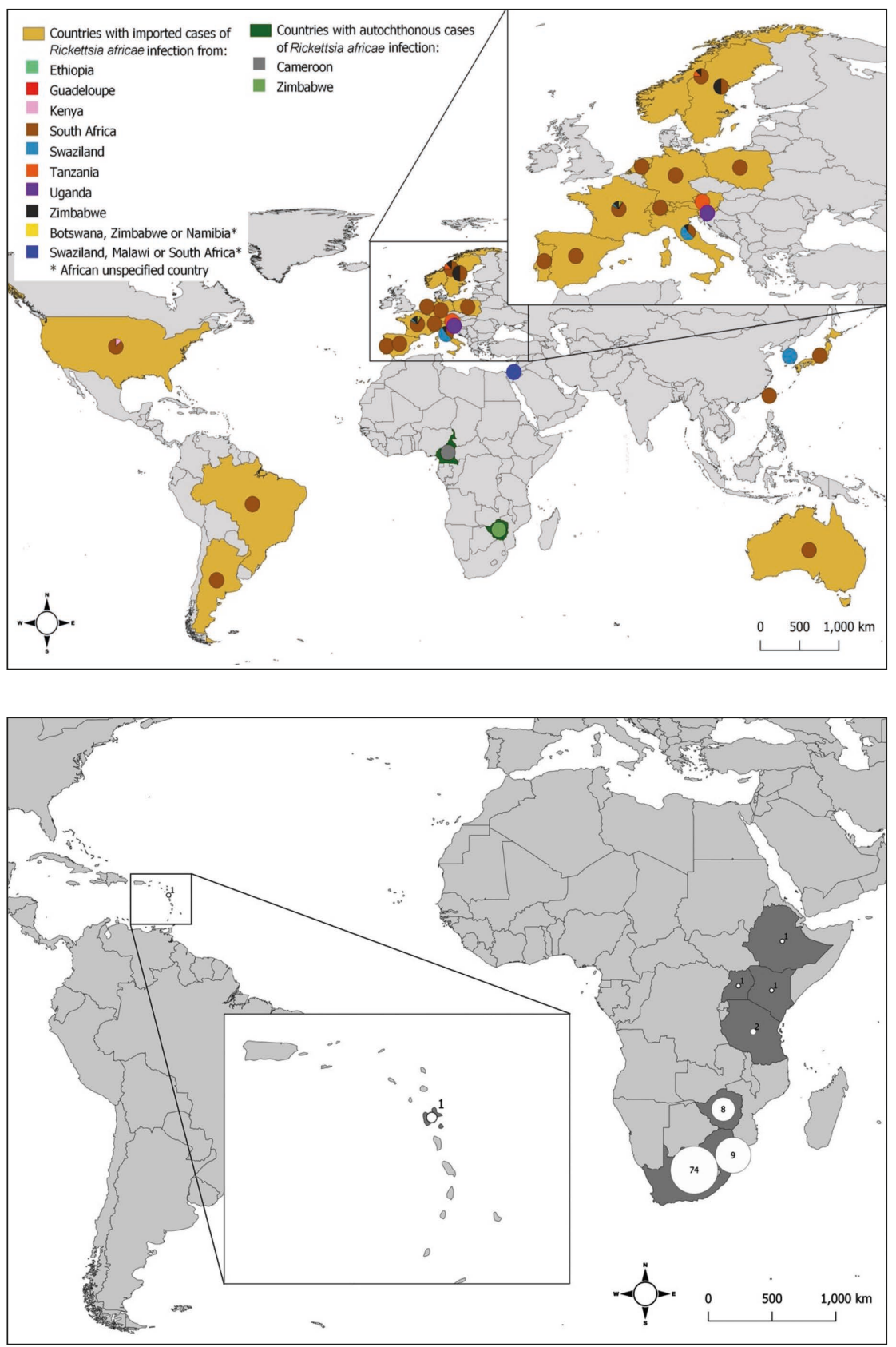

\section{Laboratory manifestations}

We analyzed hematologic and biochemical laboratory data (Table 3). From all reported cases, excluding missing information of some variables ("no data"), 70.7\% presented with abnormal laboratory findings, of which $47.2 \%$ had elevated aspartate aminotransferase (AST), 47.2\% elevated
C-reactive protein (CRP), 41.5\% elevated alanine aminotransferase (ALT), 32.1\% leukopenia, 20.8\% thrombocytopenia, and $15.1 \%$ elevated lactate dehydrogenase or gamma-glutamyl transferase. Five or fewer patients had other altered laboratory parameters such as increased erythrocyte sedimentation rate, alkaline phosphatase, creati- 
Table 2 - Clinical features of confirmed cases of Rickettsia africae infection

\begin{tabular}{|l|c|}
\hline & $\begin{array}{c}\text { Total cases } \\
n=108\end{array}$ \\
\hline Fever & $97 / 108(89.8 \%)$ \\
Eschar & $93 / 108(86.1 \%)$ \\
Single & $42 / 93(45.2 \%)$ \\
Multiple & $51 / 93(54.8 \%)$ \\
Regional lymphadenopathy & $55 / 108(50.9 \%)$ \\
Lymphangitis & $12 / 108(11.1 \%)$ \\
Rash & $45 / 108(41.7 \%)$ \\
Papular & $27 / 44(61.4 \%)^{\mathrm{a}}$ \\
Macular & $25 / 44(56.8 \%)^{\mathrm{a}}$ \\
Vesicular & $21 / 44(47.7 \%)^{\mathrm{a}}$ \\
Other & \\
Headache & $65 / 108(60.2 \%)$ \\
Myalgia & $53 / 108(49.1 \%)$ \\
Chills & $19 / 108(17.6 \%)$ \\
Arthralgia & $10 / 108(9.3 \%)$ \\
Fatigue & $10 / 108(9.3 \%)$ \\
Malaise & $7 / 108(6.5 \%)$ \\
\hline
\end{tabular}

tSome cases presented a mixed type of rash.

a 1 case [13] was excluded due to missing data.

Table 3 - Laboratory findings of confirmed cases of Rickettsia africae infection

\begin{tabular}{|l|c|}
\hline \multicolumn{1}{|c|}{ Laboratory findings } & $\begin{array}{c}\text { Total cases } \\
n=108\end{array}$ \\
\hline Abnormal laboratory findings* & $53 / 75(70.7 \%)$ \\
$\uparrow$ AST & $25 / 53(47.2 \%)$ \\
$\uparrow$ CRP & $25 / 53(47.2 \%)$ \\
$\uparrow$ ALT & $22 / 53(41.5 \%)$ \\
$\downarrow$ WBC & $17 / 53(32.1 \%)$ \\
$\downarrow$ PLT & $11 / 53(20.8 \%)$ \\
$\uparrow$ LDH & $8 / 53(15.1 \%)$ \\
$\uparrow$ GGT & $8 / 53(15.1 \%)$ \\
No alterations & $22 / 75(29.3 \%)$ \\
\hline
\end{tabular}

* 33 cases $[4,13,15,19-23,26,30,31,34,37,38,43,46,54]$ were excluded due to missing data.

AST aspartate aminotransferase; CRP C-reactive protein; ALT alanine aminotransferase; WBC white-blood cells; PLT Platelets; LDH Lactate dehydrogenase; GGT gamma-glutamyl transferase.

nine, antiphospholipid antibodies, ferritin, total bilirubin, lymphopenia, leukocytosis, and monocytosis $[15,17,19,22,25,28,29,45,52,56]$. Two cases $(3.8 \%)$ were described as having "increased hepatic enzymes" not otherwise specified [39].

\section{Treatment and outcomes}

We analyzed antibiotic therapy, complications, need for hospitalization, and clinical outcomes (Table 4). From all reported cases, excluding missing information of some variables ("no data"),
Table 4 - Treatment, complications and outcomes of confirmed cases of Rickettsia africae infection

\begin{tabular}{|l|c|}
\hline & $\begin{array}{c}\text { Total cases } \\
n=108\end{array}$ \\
\hline Antibiotic therapy* & \\
Monotherapy & $83 / 90(92.2 \%)$ \\
Doxycycline & $77 / 83(92.8 \%)$ \\
Ciprofloxacin & $2 / 83(2.4 \%)$ \\
Minocycline & $1 / 83(1.2 \%)$ \\
Amoxicillin & $1 / 83(1.2 \%)$ \\
Pristinamycin & $1 / 83(1.2 \%)$ \\
Rifampicin & $1 / 83(1.2 \%)$ \\
Combined therapy & $7 / 90(7.8 \%)$ \\
Doxycycline + Ciprofloxacin & $2 / 7(28.6 \%)$ \\
Doxycycline + Amoxicillin & $1 / 7(14.3 \%)$ \\
Doxycycline + Amoxicillin + & $1 / 7(14.3 \%)$ \\
Gentamicin & $1 / 7(14.3 \%)$ \\
Doxycycline + Amoxicillin + Oxacillin & $1 / 7(14.3 \%)$ \\
Minocycline + Ciprofloxacin & $1 / 7(14.3 \%)$ \\
Cotrimoxazol + Erythromycin & $4 / 108(3.7 \%)$ \\
\hline Complications & $2 / 108(1.9 \%)$ \\
Purpuric cellulitis & $1 / 108(0.9 \%)$ \\
Myocarditis & $1 / 108(0.9 \%)$ \\
Neurological syndrome & \\
\hline Need for hospitalization ${ }^{+}$ & $9 / 72(12.5 \%)$ \\
Yes & $63 / 72(87.5 \%)$ \\
\hline No & \\
\hline Clinical outcome ${ }^{+}$ & $72 / 72(100 \%)$ \\
\hline Recovery & \\
\hline
\end{tabular}

*18 cases $[13,16,22,24,26]$ were excluded due to missing data.

+36 case $[4,13,16,22,24,26,43,51]$ were excluded due to missing data.

most of patients received antibiotic monotherapy $(92.2 \%)$, and the remaining $7.8 \%$ received more than one antibiotic. From patients who received monotherapy, doxycycline was administered in $92.8 \%$, ciprofloxacin in $2.4 \%$, and minocycline, amoxicillin, pristinamycin or rifampicin in $1.2 \%$. In all patients but one who received combined antibiotic therapy, at least one tetracycline antimicrobial (doxycycline or minocycline) was included. Complications occurred in $3.7 \%$ of cases, including purpuric cellulitis $(1.9 \%)$, myocarditis $(0.9 \%)$ and neurological syndrome $(0.9 \%)$. Hospitalization was required in only $12.5 \%$, and all cases had complete clinical recovery.

\section{DISCUSSION}

Demographic and epidemiological data

Our results show that $R$. africae infection, ATBF, is more frequent in the age group of $18-64$ years 
and has slightly greater incidence in males. This demographic pattern has also been described for other rickettsioses including Mediterranean spotted fever in Spain, scrub typhus in Australia [60, 61], Rickettsia rickettsii rickettsiosis in Brazil and Rickettsia parkeri rickettsiosis $[62,63]$. Comparing our results with published cohorts or case series of SFG rickettsiosis in travelers and ATBF, similar results have been reported regarding sex and age $[10,11,63,64]$. In our systematic review, although differences in sex frequency of infection is not high, predominance for males can be explained due to higher risk outdoor activities, which can favor the direct or indirect contact with tick bites (e.g., hunting, hiking, forestry, safari, among others) that are usually more often engaged in by males [65]. On the other hand, although travel has become an activity for all ages, youth and adults are the ones who travel the most, and ATBF is the most important rickettsial disease in travel medicine; thus, these two aspects could explain our results regarding age group related to $R$. africae infection $[66,67]$.

Considering the geographic origin of cases, we found that autochthonous cases represent less than $10 \%$ of all reported confirmed infections. Despite the facts that sub-Saharan Africa is endemic for ATBF and $R$. africae is widely distributed in Africa [68], autochthonous symptomatic cases seem to be rarely reported, probably because of many factors such as the mild clinical course of the disease, the infection in African people at an early age (developing an anamnestic antibody response), failure to detect classical signs including inoculation eschars that are not easily recognized in darkly pigmented persons, and the fact that definitive diagnosis is not established and reported, as it requires non-conventional molecular and serological tests (e.g., PCR or cross-absorption with WB) that are usually unavailable [68-70].

Data of epidemiological studies on ATBF in African communities are scarce. In 1991 Kelly et al. estimated an annual case incidence rates of ATBF as $60-80$ per 10,000 patients in Zimbabwe, and subsequent serological studies in Central Africa (Cameroon) have been reported antibodies reactive with R. africae between $12-52 \%$, and $32 \%$ among acutely febrile patients [70-72]. Interestingly, a recent study which assessed the knowledge, attitudes and practices on ATBF of rural livestock communities in the Eastern Cape Province of South Afri- ca, showed that despite participants had frequent exposure to tick bites, they were not aware of $R$. africae infection nor that ticks are vectors of the disease [73], raising concerns about the potential risks posed by ATBF in the rural populace.

On the other hand, the mentioned literature has stated that ATBF is a frequent rickettsial acute undifferentiated febrile illness in travelers, and our results confirm this, as we found more than $90 \%$ of all reported cases occurred in travelers $[67,74-$ 76]. European travelers represented more than the $80 \%$ of all imported infections, with France the country where most cases have been diagnosed, and South Africa the country where most $R$. africae infections were acquired. Thus, our results are in line with the multicenter GeoSentinel analysis of rickettsial diseases in international travelers, 1996-2008, which pointed out that Europeans have the highest frequency of infection, probably due to greater predilection to travel to underdeveloped countries for outdoor activities, and because more than $80 \%$ of SFG rickettsiosis has occurred in travelers in sub-Saharan Africa [67].

Interestingly, persons from the U.S. returning from Africa with a SFG rickettsiosis have been travelled to many countries including Congo, Gabon, Gambia, Liberia, Togo, Mozambique, Zambia, Botswana, Zimbabwe, Swaziland, Tanzania, Uganda, Kenya, Ethiopia and South Africa, and our results revealed confirmed $R$. africae cases in the last seven countries cited above [10]. Overall, the increasing tourism in rural areas such as Kruger National Park in South Africa, with outdoor activities, contribute to the high risk of exposure to vector-borne diseases [77].

Outbreaks of ATBF have been reported in groups of travelers, resulting in clusters cases, one of the most important epidemiological characteristics of $R$. africae infection [16, 78]. Group activities in endemic areas such as hunting, hiking, safari and other outdoor tourist activities represents an important risk factor for the development of infection in clusters $[8,11,19]$. Our results show that almost $40 \%$ of all reported cases occurred in clusters. Even though cluster infection frequency was not as high as other epidemiological aspects, it seems to be characteristic of ATBF and an important criterion for epidemiological diagnosis, since it is not a common feature in other SFG rickettsioses, with only few reported clustered cases in $R$. rickettsii and Rickettsia japonica infections [79-82]. 
In our analysis, tick exposure (tick-bite or seeing tick) was reported in $60 \%$ of cases, which is close to the percentage described for SFG rickettsioses in U.S. travelers returning from Africa (55\%) [10], but not as high as other rickettsioses such as $R$. rickettsii in Brazil (72\%) and $R$. parkeri rickettsiosis $(92 \%)[63,83]$. Tick vectors, $A$. hebraeum and $A$. variegatum, are reservoirs of $R$. africae as they transmit the infection to their offspring by transovarial transmission; thus, not only the adult stage is involved in tick-bite transmission, and also larvae and nymphs, which are smaller, not easy to see and be recognized by people, explaining why many patients do not report history of tick exposure during travel [84, 85].

Curiously, a recent study described the first detection of an A. variegatum infesting a sheep on the island of Sardinia, Italia, and the detection of $R$. africae in this tick $[86,87]$. The authors pointed the above as an occasional finding, probably linked to the migrating birds from Africa during summer [87]. In fact, previous Italian studies had reported R. africae in Ixodes ricinus, and in endemic ticks of African continent, like Amblyomma and Hyalomma, removed from migratory birds, as well, raising the needed to better investigate the role of these animals in the epidemiology of ATBF in non-endemic areas $[86,88]$.

\section{Clinical data}

Clinically, R. africae infection presents classical features of tick-borne rickettsiosis, such as fever, eschar at the tick-bite site, rash and nonspecific symptoms including headache, myalgia, regional lymphadenopathy, among others [89, 90]; however, previously published cohorts or case series of ATBF have emphasized eschar as usually multiple, regional lymphadenopathy present even in the absence of the eschar, presence of lymphangitis, and cutaneous rash usually being absent or developed only close to the inoculation site [11, 64]. In our review, more than $80 \%$ of the cases had fever and inoculation eschar, rash was not a common sign as it was present in less than $50 \%$ of cases, and frequent nonspecific symptoms were headache and myalgia. Considering single or multiple eschars, our results revealed that more than $50 \%$ of cases developed multiple eschars, which is in line with previous publications [8, 11]. Multiple eschars develop due to the aggressive behavior of $A$. variegatum and $A$. hebraeum, high portion of which carry R. africae, thus people are often bitten by multiple infected ticks simultaneously $[8,85$, $91,92]$. Multiple eschars seem to be a characteristic of ATBF; this clinical finding has described in other rickettsioses such as infections caused by $R$. conorii or Orientia tsutsugamushi [93, 94].

Comparing our results with other studies on confirmed and probable cases of ATBF and SFG rickettsioses in U.S. travelers returning from Africa, our data was more similar to the reported of Raoult et al. regarding fever $(88 \%)$, inoculation eschar $(95 \%)$ (single [ $46 \%$ ] or multiple [54\%]) and rash $(46 \%)[10,11,64]$. In addition, it is worth mentioning that our results identified lymphangitis as a clinical finding in $11 \%$ of $R$. africae infections, highlighting, as other authors, that it is not a specific feature of infection caused by Rickettsia sibirica subsp. mongolitimonae [12].

\section{Laboratory features}

Regarding laboratory features, rickettsial diseases, whether as mild or severe illness, present common abnormalities such as mild leukopenia, increased C-reactive protein, thrombocytopenia, and moderately elevated transaminases $[95,96]$. Our results show that at least $70 \%$ of ATBF cases had at least one abnormal laboratory parameter. Increases in transaminases, C-reactive protein and leukopenia were the main features described in $R$. africae infection, which are common in rickettsioses $[95,96]$; however, none of them is specific for this rickettsiosis. Unfortunately, we were unable to analyze levels of these laboratory parameters.

\section{Treatment, complications and outcomes}

Regarding antibiotic therapy, tetracycline-class antibiotics (doxycycline and minocycline) were used in more than $90 \%$ and $80 \%$ of patients which received monotherapy and bitherapy, respectively, which is in line with this antibiotics-class as the therapy of choice for rickettsioses [97]. Thus, it is probable that in cases treated with betalactams (ineffective against rickettsiae) and a tetracycline was effective treatment for the rickettsial infection. Only one patient of bitherapy did not receive a tetracycline-class antibiotic. Other antibiotics that are effective in the analyzed cases were ciprofloxacin, pristinamycin, and rifampicin $[97,98]$. One patient was treated with a $\beta$-lactamgroup antibiotic (amoxicillin), which is ineffective for treatment of rickettsiosis; nevertheless, this 
patient did not require hospitalization and had a full clinical recovery $[15,97]$.

Complications in R. africae infection are rare, and we found them in less than $5 \%$ of confirmed cases. They included purpuric cellulitis, neurological syndrome and myocarditis. Other complications reported in the scientific literature, considering probable ATFB cases, included convalescent-phase asthenia, reactive arthritis and peripheral neuropathy $[65,99]$.

Fatal outcomes have never been reported for ATBF. Moreover, according to our results, hospitalization was reported in less than $15 \%$ of cases, and compared with severe rickettsiosis such as $R$. rickettsii and $R$. conorii infections [87, 100], ATBF has a mild clinical course and a favorable prognosis [8].

\section{CONCLUSIONS}

This systematic review provides a thorough evaluation of clinical, epidemiological, and laboratory features of $R$. africae infection, ATBF. The disease presents as a mild febrile illness, associated with multiple eschars in half of the cases, with a tick exposure not always recognized and occurring in cluster in a third of cases. Increased transaminases, C-reactive protein and leukopenia are the main laboratory features. The disease is not fatal, but complications can occur. Travelers to endemic regions for outdoor activities in sub-Saharan Africa are at risk of acquiring $R$. africae infection. As far as the molecular diagnostic methods are available to identify the Rickettsia species, it must be important a routinely microorganism detection in ticks that bite humans, and in clinical samples from people with history of tick-bites.

\section{Authors' contributions}

CRSR and ÁAFM designed the study and searched the literature. CRSR did the systematic review and wrote the draft manuscript. CRSR and ÁAFM did the data analysis, data interpretation, critically reviewed the methods and results, and wrote the original manuscript. CRSR and ÁAFM have verified the underlying data. CRSR and ÁAFM have accessed to verified the underlying data.

\section{Acknowledgments}

We thank Dr. David H. Walker for providing constructive reviews of the manuscript. We are grate- ful to Isabella Fontana for preparing the maps of Figure 2 and 3. ÁAFM is supported by a Fogarty fellowship under grant 2D43TW010331.

\section{Conflicts of interest}

The authors declare that the research was conducted in the absence of any commercial or financial relationships that could be construed as a potential conflict of interest.

\section{REFERENCES}

[1] Mendelson M, Han PV, Vincent P, et al. Regional variation in travel-related illness acquired in Africa, March 1997-May 2011. Emerg Infect Dis. 2014; 20 (4), 532-41.

[2] Eldin C, Parola P. Update on tick-borne bacterial diseases in travelers. Curr Infect Dis Rep. 2018; 20 (7), 17. [3] Pijper A, Crocker CG. Rickettsioses of South Africa. $S$ Afr Med J. 1938; 12 (17), 613-30.

[4] Kelly P, Matthewman L, Beati L, et al. African tickbite fever: a new spotted fever group rickettsiosis under an old name. Lancet 1992; 340 (8825), 982-3.

[5] Burgdorfer W, Ormsbee RA, Schmidt ML, Hoogstraal H. A search for the epidemic typhus agent in Ethiopian ticks. Bull World Health Organ. 1973; 48 (5), 563-9.

[6] Kelly PJ, Beati L, Matthewman LA, Mason PR, Dasch GA, Raoult D. A new pathogenic spotted fever group rickettsia from Africa. J Trop Med Hyg. 1994; 97 (3), 129-37.

[7] Kelly PJ, Beati L, Mason PR, Matthewman LA, Roux V, Raoult D. Rickettsia africae sp. nov., the etiological agent of African tick bite fever. Int J Syst Bacteriol. 1996; 46 (2), 611-4.

[8] Jensenius M, Fournier PE, Kelly P, Myrvang B, Raoult D. African tick bite fever. Lancet Infect Dis. 2003; 3 (9), 557-64.

[9] Kelly P, Lucas H, Beati L, Yowell C, Mahan S, Dame J. Rickettsia africae in Amblyomma variegatum and domestic ruminants on eight Caribbean islands. J Parasitol. 2010; 96 (6), 1086-8.

[10] Cherry CC, Denison AM, Kato CY, Thornton K, Paddock CD. Diagnosis of Spotted Fever Group Rickettsioses in U.S. Travelers Returning from Africa, 20072016. Am J Trop Med Hyg. 2018; 99 (1), 136-42.

[11] Raoult D, Fournier PE, Fenollar F, Jensenius M, Prioe T, de Pina JJ. Rickettsia africae, a tick-borne pathogen in travelers to sub-Saharan Africa. New Engl J Med. 2001; 344 (20), 1504-10.

[12] Parola P, Paddock CD, Socolovschi C, Labruna MB, Mediannikov O, Kernif T. Update on tick-borne rickettsioses around the world: a geographic approach. Clin Microbiol Rev. 2013; 26 (4), 657-702.

[13] Ndip LM, Fokam EB, Bouyer DH, Ndip RN, Titanji 
VP, Walker DH. Detection of Rickettsia africae in patients and ticks along the coastal region of Cameroon. Am J Trop Med Hyg. 2004; 71 (3), 363-6.

[14] Bouceiro-Mendes R, Mendonça-Sanches M, Soares-de-Almeida L, Correia-Fonseca I. Inoculation eschars and fever: a case of African tick bite fever. J Port Soc Dermatol Venereol 2019; 77 (3).

[15] Brouqui P, Harle JR, Delmont J, Frances C, Weiller PJ, Raoult D. African tick-bite fever. An imported spotless rickettsiosis. Arch Intern Med. 1997; 157 (1), 119-24.

[16] Fournier PE, Roux V, Caumes E, Donzel M, Raoult D. Outbreak of Rickettsia africae infections in participants of an adventure race in South Africa. Clin Infect Dis. 1998; 27 (2), 316-23.

[17] Parola P, Jourdan J, Raoult D. Tick-borne infection caused by Rickettsia africae in the West Indies. New Engl J Med. 1998; 338 (19), 1391.

[18] Fournier PE, Beytout J, Raoult D. Tick-transmitted infections in Transvaal: consider Rickettsia africae. Emerg Infect Dis. 1999; 5 (1), 178-81.

[19] Jensenius M, Hasle G, Henriksen AZ, Vene S, Raoult D, Bruu AL. African tick-bite fever imported into Norway: presentation of 8 cases. Scand J Infect Dis. 1999; 31 (2), 131-3.

[20] Sexton DJ, Corey GR, Greenfield JC, Jr., Burton CS, Raoult D. Imported African tick bite fever: a case report. Am J Trop Med Hyg. 1999; 60 (5), 865-7.

[21] Roux O, Desruelles F, Delaunay P, Le Fichoux Y, Ortonne JP. Ticks and photo safari in South Africa. Brit J Dermatol. 2000; 143 (5), 1109-10.

[22] Caruso G, Zasio C, Guzzo F, et al. Outbreak of African tick-bite fever in six Italian tourists returning from South Africa. Eur J Clin Microbiol. 2002; 21 (2), 133-6.

[23] Delfos NM, Schippers EF, Raoult D, Visser LG. Fever and vesicular rash in a traveler returning from South Africa. Clin Infect Dis. 2004; 39 (5), 700-1+41-42.

[24] Kim J, Smith KJ, Naefie R, Skelton H. Histopathologic features of and lymphoid populations in the skin of patients with the spotted fever group of rickettsiae: Southern Africa. Int J Dermatol. 2004; 43 (3), 188-94.

[25] Oteo JA, Portillo A, Blanco JR, Ibarra V, Santibáñez S. Infección por Rickettsia africae. Tres casos confirmados por reacción en cadena de la polimerasa. Med Clin-Barcelona. 2004; 122 (20), 786-8.

[26] Lepidi H, Fournier PE, Raoult D. Histologic features and immunodetection of African tick-bite fever eschar. Emerg Infect Dis. 2006; 12 (9), 1332-7.

[27] Reshef R, Levo Y, Giladi M. African tick bite fever in a returned traveler. Israel Med Assoc J. 2007; 9 (9), 680-1.

[28] Bouvresse S, Del Giudice P, Franck N, et al. Two cases of cellulitis in the course of African tick bite fever: a fortuitous association? Dermatology. 2008; 217 (2), 140-2.

[29] Roch N, Epaulard O, Pelloux I, et al. African tick bite fever in elderly patients: 8 cases in French tourists returning from South Africa. Clin Infect Dis. 2008; 47 (3), e28-35.
[30] Tsai YS, Wu YH, Kao PT, Lin YC. African tick bite fever. J Formos Med Assoc 2008; 107 (1), 73-6.

[31] Wölfel R, Essbauer S, Dobler G. Diagnostics of tickborne rickettsioses in Germany: A modern concept for a neglected disease. Int J Med Microbiol. 2008; 298 (Suppl. 1), 368-74.

[32] Consigny PH, Schuett I, Fraitag S, Rolain JM, Buffet P. Unusual location of an inoculation lesion in a traveler with African tick-bite fever returning from South Africa. J Travel Med. 2009; 16 (6), 439-40.

[33] Méchaï F, Han Y, Gachot B, et al. Pristinamycin for Rickettsia africae infection. J Travel Med. 2009; 16 (2), 136-7. [34] Mortada R, El Fakih R, Saliba W, A. Moore T. Skin lesions in a returning traveler. Infect Dis Clin Prac. 2009; 17 (2), 108-10.

[35] Stephany D, Buffet P, Rolain JM, Raoult D, Consigny PH. Rickettsia africae infection in man after travel to Ethiopia. Emerg Infect Dis. 2009; 15 (11), 1867-9.

[36] Tappe D, Dobler G, Stich A. Tache noire in African tick bite fever. Am J Trop Med Hyg. 2009; 81 (5), 733-4.

[37] Tsai KH, Lu HY, Huang JH, et al. African tick bite Fever in a Taiwanese traveler returning from South Africa: molecular and serologic studies. Am J Trop Med Hyg 2009; 81 (5), 735-9.

[38] Wang JM, Hudson BJ, Watts MR, et al. Diagnosis of Queensland tick typhus and African tick bite fever by PCR of lesion swabs. Emerg Infect Dis. 2009; 15 (6), 963-5.

[39] Althaus F, Greub G, Raoult D, Genton B. African tick-bite fever: a new entity in the differential diagnosis of multiple eschars in travelers. Description of five cases imported from South Africa to Switzerland. Int J Infect Dis. 2010; 14 (Suppl. 3), e274-6.

[40] Wieten RW, Hovius JW, Groen EJ, et al. Molecular diagnostics of Rickettsia africae infection in travelers returning from South Africa to The Netherlands. Vector Borne Zoonot Dis. 2011; 11 (12), 1541-7.

[41] Fujisawa T, Kadosaka T, Fujita H, et al. Rickettsia africae infection in a Japanese traveller with many tick bites. Acta Derm-Venereol. 2012; 92 (4), 443-4.

[42] Gonzalez FA, Martins J, Coelho M, et al. African tick bite fever in a portuguese traveler returning from South Africa. Infect Dis Clin Prac. 2012; 20 (2), 150-1.

[43] Socolovschi C, Renvoisé A, Brouqui P, Parola P, Raoult D. The use of eschar swabs for the diagnosis of African tick-bite fever. Ticks Tick-Borne Dis. 2012; 3 (5-6), 361-3.

[44] Chmielewski T, Szymanek A, Mączka I, Fiecek B, Simon K, Tylewska-Wierzbanowska S. Case report of African tick-bite fever from Poland. Postep Derm Alergol. 2013; 30 (6), 396-8.

[45] Zammarchi L, Farese A, Trotta M, Amantini A, Raoult D, Bartoloni A. Rickettsia africae infection complicated with painful sacral syndrome in an Italian traveller returning from Zimbabwe. Int J Infect Dis. 2014; 29, 194-6. 
[46] Bohaty BR, Hebert AA, Baden LR. African tick-bite fever after a game-hunting expedition. New Engl J Med. 2015; 372 (10), e14.

[47] Mathur P, Shah S, Beck M. Fever. Eschars on right leg and groin. Inguinal lymphadenopathy. Dx? J Fam Practice. 2015; 64 (11), 720-2.

[48] Tomasiewicz K, Krzowska-Firych J, Bielec D, Socolovschi C, Raoult D. First case of imported African tickbite fever in Poland - Case report. Ann Agr Env Med. 2015; 22 (3), 412-3.

[49] Bogovic P, Lotric-Furlan S, Korva M, Avsic-Zupanc T. African tick-bite fever in a traveler returning to Slovenia from Uganda. Emerg Infect Dis. 2016; 22 (10), 1848-9. [50] Harrison N, Burgmann H, Forstner C, et al. Molecular diagnosis of African tick bite fever using eschar swabs in a traveller returning from Tanzania. Wien Klin Wochenschr. 2016; 128 (15-16), 602-5.

[51] Hauser N, Arzomand Z, Fournier J, Breen C, Jamali L, Cossman J. A case of African tick-bite fever in a returning traveler. IDCases. 2016; 5, 78-9.

[52] Albízuri Prado F, Sánchez A, Feito M, Mayor A, Rodriguez A, de Lucas R. Fever and multiple eschars after an African safari: report of three cases. Pediatr Dermatol. 2017; 34 (4), e179-e81.

[53] Nilsson K, Wallménius K, Rundlöf-Nygren $P$, Strömdahl S, Påhlson C. African tick bite fever in returning Swedish travellers. Report of two cases and aspects of diagnostics. Infect Ecol Epidemiol. 2017; 7 (1), 1343081.

[54] Strand A, Paddock CD, Rinehart AR, et al. African tick bite fever treated successfully with rifampin in a patient with doxycycline intolerance. Clin Infect Dis. 2017; 65 (9), 1582-4.

[55] Angerami RN, Krawczak FS, Nieri-Bastos FA, et al. First report of African tick-bite fever in a South American traveler. SAGE Open Med Case Rep 2018; 6: $2050313 \times 18775301$.

[56] Fralish MS, Mangalindan KE, Farris CM, Jiang J, Green MC, Blaylock JM. African tick-bite fever. Am J Med. 2020; 133 (9), 1051-3.

[57] Ganjuur N, Abu Rached N, Doerler M, Gambichler T. Rickettsialpox caused by Rickettsia africae in an elderly woman. Clin Exp Dermatol. 2020; 45 (7), 905-7.

[58] Lee W, Seong H, Kim JH, et al. A case of African tick-bite fever in a returning traveler from southern Africa. Infect Chemother. 2020. doi: 10.3947/ic.2019.0073.

[59] Armitano RI, Borras PJ, Govedic F, Prieto MA, Guillemi E. African tick bite fever: first imported cases diagnosed by PCR in Argentina. Travel Med Infect Dis 2021; 40, 01959. doi: 10.1016/j.tmaid.2020.101959.

[60] Herrador Z, Fernandez-Martinez A, Gomez-Barroso D, et al. Mediterranean spotted fever in Spain, 19972014: epidemiological situation based on hospitalization records. PloS One. 2017; 12 (3), e0174745.

[61] Stewart AGA, Smith S, Binotto E, McBride WJH, Hanson J. The epidemiology and clinical features of rickettsial diseases in North Queensland, Australia: Implications for patient identification and management. PLoS Negl Trop Dis. 2019; 13 (7), e0007583.

[62] Oliveira S, Guimarães J, Reckziegel G, et al. An update on the epidemiological situation of spotted fever in Brazil. J Venom Anim Toxins Incl Trop Dis. 2016; 22; 22 (1), 22.

[63] Silva-Ramos CR, Hidalgo M, Faccini-Martínez ÁA. Clinical, epidemiological, and laboratory features of Rickettsia parkeri rickettsiosis: A systematic review. Ticks Tick-Borne Dis. 2021; 101734.

[64] Jensenius M, Fournier PE, Vene S, et al. African tick bite fever in travelers to rural sub-Equatorial Africa. Clin Infect Dis. 2003; 36 (11), 1411-7.

[65] World Health Organization. Regional Office for the Western P. Taking sex and gender into account in emerging infectious disease programme: an analytical framework: Manila: WHO Regional Office for the Western Pacific; 2011.

[66] Han P, Balaban V, Marano C. Travel characteristics and risk-taking attitudes in youths traveling to nonindustrialized countries. J Travel Med. 2010; 17 (5), 316-21. [67] Jensenius M, Davis X, von Sonnenburg F, et al. Multicenter GeoSentinel analysis of rickettsial diseases in international travelers, 1996-2008. Emerg Infect Dis. 2009; 15 (11), 1791-8.

[68] Kelly PJ. Rickettsia africae in the West Indies. Emerg Infect Dis 2006; 12 (2), 224-6.

[69] Walker DH, Ismail N, Olano JP, Valbuena G, McBride J. Pathogenesis, immunity, pathology, and pathophysiology in rickettsial diseases. In Rickettsial diseases. 2007; 15-26.

[70. Ndip LM, Bouyer DH, Travassos Da Rosa AP, Titanji VP, Tesh RB, Walker DH. Acute spotted fever rickettsiosis among febrile patients, Cameroon. Emerg Infect Dis. 2004; 10 (3), 432-7.

[71. Kelly PJ, Mason PR, Matthewman LA, Raoult D. Seroepidemiology of spotted fever group rickettsial infections in humans in Zimbabwe. J Trop Med Hyg. 1991; 94 (5), 304-9.

[72] Ndip LM, Biswas HH, Nfonsam LE, et al. Risk factors for African tick-bite fever in rural central Africa. Am J Trop Med Hyg. 2011; 84 (4), 608-13.

[73] Katswara T, Mukaratirwa S. Knowledge, attitudes and practices on African tick bite fever of rural livestock communities living in a livestock-wildlife interface area in the Eastern Cape Province of South Africa. BMC Infect Dis. 2021; 21 (1), 497.

[74] Delord M, Socolovschi C, Parola P. Rickettsioses and Q fever in travelers (2004-2013). Travel Med Infect Dis. 2014; 12 (5), 443-58.

[75] Sanford CA, Fung C. Illness in the returned international traveler. Med Clin North Am. 2016; 100 (2), 393-409. [76] Parola P, Paddock CD. Travel and tick-borne diseases: Lyme disease and beyond. Travel Med Infect Dis. 2018; 26, 1-2. 
[77] Durrheim DN, Braack L, Grobler D, Bryden H, Speare R, Leggat PA. Safety of travel in South Africa: The Kruger National park. J Travel Med. 2001; 8 (4), 176-91.

[78] Smoak BL, McClain JB, Brundage JF, et al. An outbreak of spotted fever rickettsiosis in U.S. Army troops deployed to Botswana. Emerg Infect Di.s 1996; 2 (3), 217-21. [79] Rotz L, Callejas L, McKechnie D, et al. An epidemiologic and entomologic investigation of a cluster of Rocky Mountain spotted fever cases in Delaware. Del Med J. 1998; 70 (6), 285-91.

[80] Londoño AF, Arango-Ferreira C, Acevedo-Gutiérrez LY, et al. A cluster of cases of Rocky Mountain spotted fever in an area of Colombia not known to be endemic for this disease. Am J Trop Med Hyg. 2019; 101 (2), 336-42.

[81] Matsuura H, Yokota K. Case report: family cluster of Japanese spotted fever. Am J Trop Med Hyg. 2018; 98 (3), 835-7.

[82] Rozental T, Ferreira MS, Gomes R, et al. A cluster of Rickettsia rickettsii infection at an animal shelter in an urban area of Brazil. Epidemiol Infect. 2015; 143 (11), 2446-50.

[83] Angerami RN, Câmara M, Pacola MR, et al. Features of Brazilian spotted fever in two different endemic areas in Brazil. Ticks Tick-Borne Dis. 2012; 3 (5), 346-8. [84] Socolovschi C, Huynh TP, Davoust B, Gomez J, Raoult D, Parola P. Transovarial and trans-stadial transmission of Rickettsiae africae in Amblyomma variegatum ticks. Clin Microbiol Infect. 2009; 15, 317-8.

[85] Kelly PJ, Mason PR. Transmission of a spotted fever group rickettsia by Amblyomma hebraeum (Acari: Ixodidae). J Med Entomol. 1991; 28 (5), 598-600.

[86. Guccione C, Colomba C, Tolomeo M, Trizzino M, Iaria C, Cascio A. Rickettsiales in Italy. Pathogens. 2021; 10 (2), 181.

[87] Pintore E, Olivieri E, Floriano AM, Sassera D, Sanna N, Garippa G. First detection of Amblyomma variegatum and molecular finding of Rickettsia africae in Sardinia, Italy. Ticks Tick Borne Dis. 2021; 12 (1), 101561.

[88. Toma L, Mancini F, Di Luca M, et al. Detection of microbial agents in ticks collected from migratory birds in central Italy. Vector Borne Zoonotic Dis. 2014; 14 (3), 199-205.
[89] Blanton LS. The rickettsioses: a practical update. Infect Dis Clin North Am. 2019; 33 (1), 213-29.

[90] Faccini-Martínez ÁA, García-Álvarez L, Hidalgo M, Oteo JA. Syndromic classification of rickettsioses: an approach for clinical practice. Int J Infect Dis. 2014; 28, 126-39.

[91] Maina AN, Jiang J, Omulo SA, et al. High prevalence of Rickettsia africae variants in Amblyomma variegatum ticks from domestic mammals in rural western Kenya: implications for human health. Vector Borne Zoonot Dis. 2014; 14 (10), 693-702.

[92] Anderson R, Scrimgeour G, Kaufman R. Responses of the tick, Amblyomma hebraeum (Acari: Ixodidae), to carbon dioxide. Exp Appl Acarol. 1998; 22, 667-81.

[93] Hwang IT, Lee JH. Unusually high number of eschars on the face of a patient with scrub typhus. Korean I Intern Med. 2011; 26 (3), 365.

[94] Mouffok N, Parola P, Lepidi H, Raoult D. Mediterranean spotted fever in Algeria-new trends. Int J Infect Dis. 2009; 13 (2), 227-35.

[95] Raoult D. Chapter 185: Introduction to Rickettsioses, Ehrlichioses, and Anaplasmosis. In Mandell, Douglas, and Bennett's Principles and Practice of Infectious Diseases Ninth Edition. (C.G. Pijper A, Eds.). Philadelphia: Elsevier; 2020; 2194-7.

[96] Tselentis Y, Gikas A. Murine typhus. In Rickettsial diseases. 2007; 37-49.

[97] Blanton LS. Rickettsiales: treatment and management of human disease. In Rickettsiales: biology, molecular biology, epidemiology, and vaccine development. (Sunil Thomas, Eds.). Cham: Springer International Publishing. 2016; 109-24.

[98] Drancourt M, Raoult D. In vitro susceptibilities of Rickettsia rickettsii and Rickettsia conorii to roxithromycin and pristinamycin. Antimicrob Agents Chemother. 1989; 33 (12), 2146-8.

[99] Jensenius M, Fournier P-E, Fladby T, et al. Subacute neuropathy in patients with African tick bite fever. Scand J Infect Dis. 2006; 38 (2), 114-8.

[100] Openshaw JJ, Swerdlow DL, Krebs JW, et al. Rocky mountain spotted fever in the United States, 2000-2007: interpreting contemporary increases in incidence. Am J Trop Med Hyg. 2010; 83 (1), 174-82. 